\title{
Comentarios a una sentencia anunciada. El proceso Lula
}

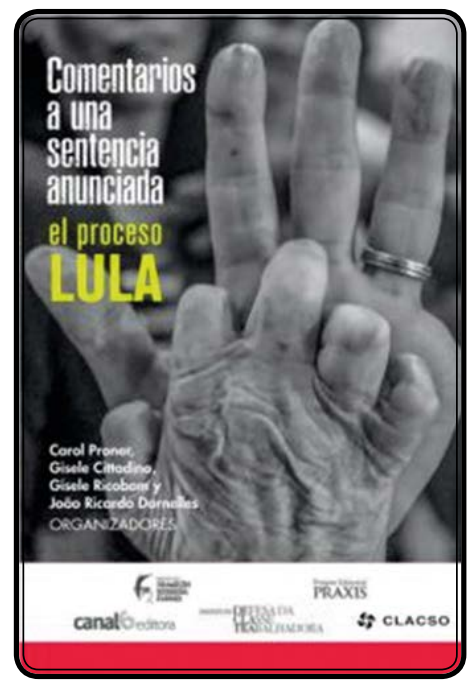

Carol Proner. Gisele Cittadino. Gisele Ricobom. João Ricardo W. Dornelles. [Organizadores]. (2018). Comentarios a una sentencia anunciada. El proceso Lula. Buenos Aires: CLACSO.

COMENTARIOS A UNA SENTENCIA ANUNCIADA: el proceso Lula es quizá el documento jurídico más importante publicado en Brasil en décadas. La presente recopilación de artículos nació de un movimiento espontáneo e importante de abogados brasileños que examinaron cuidadosamente la sentencia pronunciada en el contexto del proceso que se tramitó en la $13^{\text {a }}$ Sala Federal de Curitiba, en el caso que los medios dieron a conocer como el del "tríplex de Guarujá".

Además del carácter inédito de la condena criminal de un expresidente de la República en circunstancias políticas en teoría comparables a las de las dictaduras brasileñas del siglo pasado, la sentencia, que en gran medida era aguardada como un desenlace no sorprendente para este proceso criminal, provocó una reacción inmediata entre los que la leyeron comprometidos únicamente con el propósito de intentar entender los motivos por los que Luiz Inácio Lula da Silva está siendo castigado por haber cometido los crímenes de corrupción pasiva y lavado de activos de origen ilícito.
La condena era una certeza de antemano. Admiradores y opositores del expresidente sabían que no habría otro veredicto. La duda residía en conocer las razones de la condena, exigencia normativa de la Constitución de 1988 que, por las inevitables repercusiones políticas del mencionado proceso, mostraron el acierto de la Constituyente de 1987-1988 al elevar la fundamentación de las decisiones al nivel de garantía constitucional del proceso.

Solo recientemente, después de veinte años de intensa batalla jurídica protagonizada por Fernando Fernandes, por coincidência abogado de Paulo Tarciso Okamoto, que en este caso del "tríplex de Guarujá" figura como imputado al lado del expresidente Lula, se logró cumplir la decisión del Supremo Tribunal Federal, dando a conocer los audios de los juicios que el Superior Tribunal Militar (STM) realizó durante la dictadura de 1964-1985.

Estos juicios, vueltos públicos ahora, revelan las virtudes democráticas de la publicidad del proceso y de la exposición de las decisiones. Frases al estilo de "Voy a tomar una decisión 
revolucionaria, dejando de lado la ley, porque por la ley no se puede condenarlo de ninguna manera", dichas en los juicios por las más altas autoridades judiciales militares y civiles, en un ambiente de confidencialidad, hoy son conocidas por quienes se abocaron al trabajo de escuchar los audios de aquellas sesiones.

La exposición de las decisiones y la publicidad de los juicios son las armas pacíficas del Estado de Derecho contra arbitrariedades y abusos, además de proporcionar a los tribunales la oportunidad de una mayor calidad y eficiencia en la tarea de corregir sentencias consideradas injustas, a pesar de respaldarse en la sincera creencia de que el derecho fue aplicado al caso concreto.

Además, el trabajo de los jueces, como expresión de actividad republicana regulada por un conjunto escrupuloso de normas jurídicas materiales y procesales, está sujeto a ser conocido y garantizado no solo por las partes destinatarias directas de la sentencia.

Cada persona, interesada en la suerte de su semejante sometido a un proceso criminal, dispone de medios y recursos para evidenciar una verdadera arqueología de las razones por las que alguien es condenado o absuelto.

La publicidad del proceso y la exposición de las decisiones funcionan como escudos contra el tipo de justificación antes referido, frecuente a la época del STM, propio de los juicios políticos. En casos donde la condición de proceso político no se encubre por la forma criminal con que se presentan, es mediante la averiguación de las razones del magistrado que la ciudadanía se siente protegida o amenazada.

Si los motivos de una eventual condena corresponden a lo que prevé el corpus jurídico vigente y la ley penal está siendo aplicada en conformidad con el razonamiento dominante acerca del conjunto de conceptos y nociones producidos por la llamada dogmática penal en Brasil, ha de presumirse justificable la sentencia $\mathrm{y}$, de esta forma, su acierto dependerá de la corrección del juicio del magistrado acerca de la valoración de la prueba, que debe producirse en un ambiente de rigurosa observancia de las normas del debido proceso legal.

Sin embargo, si los conceptos y nociones canónicos del derecho penal brasileño son apartados y, además, las garantías del debido proceso son vulneradas, recurriendo el juez a criterios de valoración de la prueba y a otras prácticas procesales como mínimo altamente discutibles, lo ordinario se convierte en excepción y las señales de alerta, en la defensa del Estado de Derecho, inmediatamente deben accionarse.

En la hipótesis hay un expresivo consenso de que el derecho extranjero aparentemente sustituyó al nuestro, operándose el fenómeno que Elisabetta Grande (2009) denomina circulación simbólica de los modelos jurídicos oriundos de diferentes ámbitos de la cultura jurídica y de diferentes áreas del propio derecho.

El manejo de los conceptos y nociones siguió por este camino en la condena, reflejando convicciones particulares y presunciones formuladas en materia penal en disconformidad con el análisis de hechos sustentado en pruebas.

Si bien se trata de una simple presentación del libro, no le cuesta al lector entrever el significado, en términos de peligro para las libertades individuales, de convertir la excepción en norma, como en mi opinión queda claro en la sentencia se trata de la opción del magistrado.

Sobre este asunto subraya Janaína Matida (2017): La presunción judicial no es otra cosa que el razonamiento sobre los hechos realizados por quien juzga; es lo que se espera que exista en sistemas jurídicos en los que esté vigente la directiva de valoración libre y racional, pues cabe al juez valorar las pruebas como informaciones suficientes (o no) para la determinación de la ocurrencia de los hechos bajo discusión. $\mathrm{Su}$ cualidad está directamente vinculada a la generalización empírica que ha seleccionado; luego si la generalización no es universal, ella por definición soporta la posibilidad de excepciones. Por lo tanto, la construcción del razonamiento deberá tratar de demostrar que el caso individual es norma y no excepción. 
El razonamiento condenatorio que se apoya en la excepción, recurre retóricamente a modelos jurídicos extranjeros y traduce indebidamente conceptos penales -como salta a la vista en la condena del expresidente por corrupciónhaciendo letra muerta de la advertencia de la imposibilidad de trasplantes de género , 1 lo que habría de provocar una vívida reacción entre los estudiosos del derecho El verdadero equipo estelar de juristas, profesoras y profesores, abogados e intelectuales que seguían de cerca el proceso, se movilizó al constatar la excepcionalidad del estilo y de los argumentos empleados por el juez criminal en la decisión mencionada.

Así, todo el proceso $-\mathrm{y}$ no solamente la sentencia- fue pasado a limpio en los artículos que el lector tiene en sus manos y que son de exclusiva responsabilidad de cada autor/a.

El centenar de textos desgrana el procedimiento, aclara qué normas efectivamente están en vigencia y cómo inciden en el caso concreto. En la opinión de los autores de los artículos estas normas no fueron observadas, y su inobservancia llevó a que se dictaminase una decisión injusta.

Es relevante notar que en tiempos de juzgamiento público y de la correspondiente publicidad de la exposición no hay más lugar para dejar de aplicar la ley para condenar.

Algo del género, por lo tanto, subviertela lógica y sería difícilmente aceptable aún más en este período de inestabilidad política e inseguridad jurídica. Interrogar cada argumento, indagar en su adecuación a los procedimientos legales y en la interpretación corriente fue el método que las autoras y los autores utilizaron para verificar en qué medida fue violado o respetado el debido proceso legal.

La probabilidad de la condena delexpresidente Lula y su confirmación son mucho más que meras convicciones de un proceso bastante problemático desde cualquier ángulo.
El lector tiene consigo más que la obra de 121 autores, retratada en 101 artículos que someten todos los aspectos de la larga sentencia a un examen crítico que la ciencia penal, el derecho constitucional y otras áreas del saber consideran fundamentales para garantizar el Estado de Derecho en Brasil.

Comentarios a una sentencia anunciada: el proceso Lula es una especie de "Carta de Compromiso con la Ciudadanía, la Democracia y el Estado de Derecho".

Confiar que los tribunales harán justicia a Luiz Inácio Lula da Silva es creer que la máxima de los juicios de los años setenta, en el STM -"Voy a tomar una decisión revolucionaria, dejando de lado la ley, porque por la ley no se puede condenarlo de ninguna manera"- está definitivamente sepultada entre nosotros. Si no hay crímenes, y crímenes no hay, la absolución es la única decisión posible.

En nombre de todos los autores y todas las autoras agradezco a los que dieron vida a este documento jurídico, a esta "Carta de Compromiso con la Ciudadanía, la Democracia y el Estado de Derecho".

Sin las excepcionales, valientes y determinadas profesoras Carol Proner, Gisele Cittadino, Gisele Ricobom, y el combativo e incansable profesor João Ricardo Dornelles, lo que sería la indignación individual con la injusticia de una decisión tan trascendente no habría dado lugar a un documento del que se espera que pueda contribuir de forma efectiva para el restablecimiento del imperio del Derecho, con la absolución del expresidente Lula.

Muchas gracias, Carol Proner, Gisele Cittadino, Gisele Ricobom y João Ricardo Dornelles. Como dijo Miguel Littín, clandestino en Chile, a García Márquez (1986): "hay actos que aparentemente son valientes, pero que en el fondo son de compromiso con la dignidad cívica. Ustedes son corajudos y nos incentivaron a realizar la lucha pacífica por la dignidad cívica". 


\section{Bibliografía}

García Márquez, G. (1986). La aventura de Miguel Littin, clandestino en Chile. México: Diana.

Grande, E. (2009) Imitação e direito: hipóteses sobre a circulação dos modelos (Porto Alegre: Fabris) Trad. L. F. Sgarbossa.

Hendler, E. S. (2006). Derecho. Derecho penal y procesal penal de los Estados Unidos (Buenos Aires: Ad-hoc).

Matida, J. (2017) Em defesa de um conceito jurídico de presunção, Tesis doctoral (mimeo)

\section{Geraldo Prado}

De la Presentación del libro, pp. 13-17 


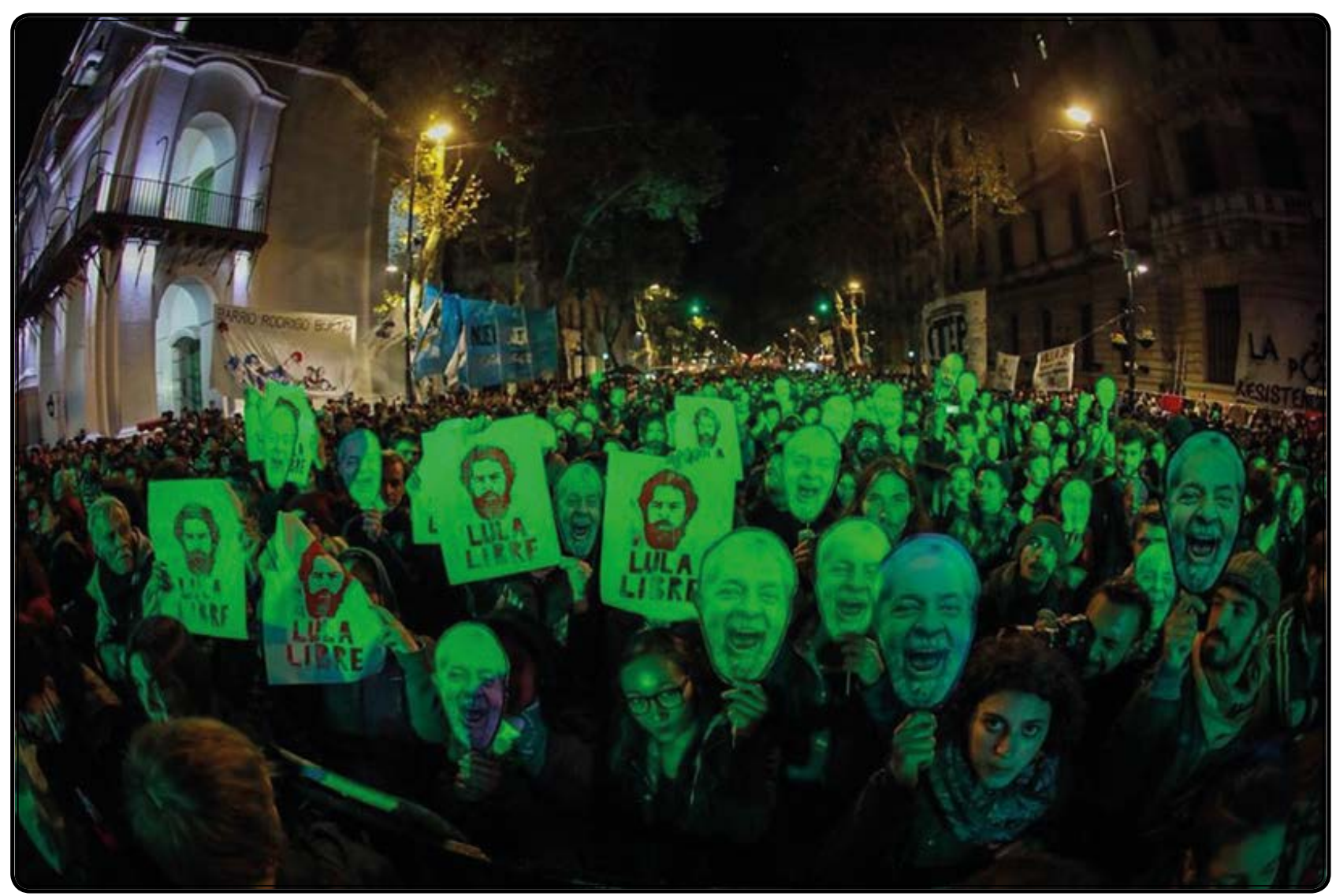

Hay que seguir, siempre. 